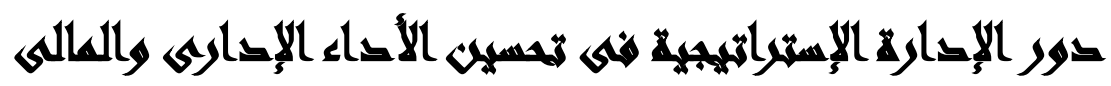

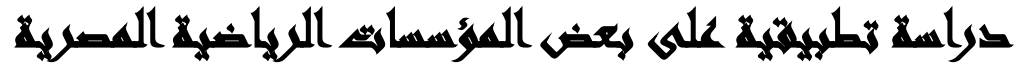

[19]

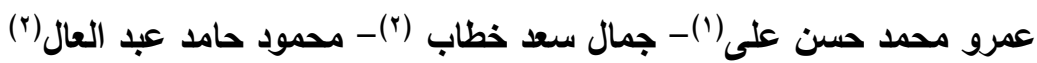

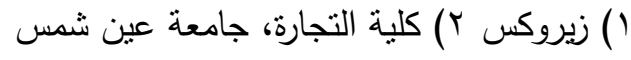

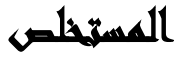

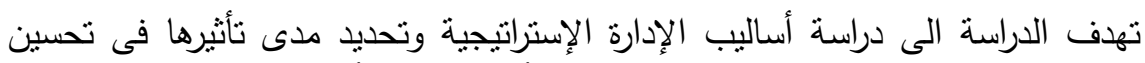

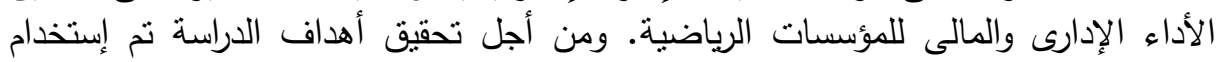

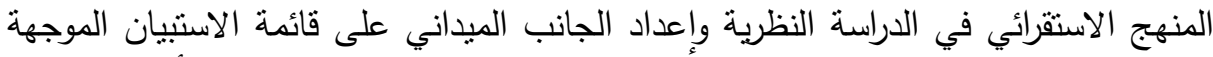

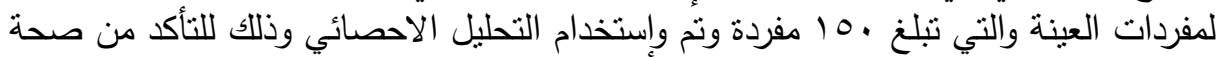

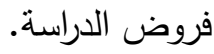

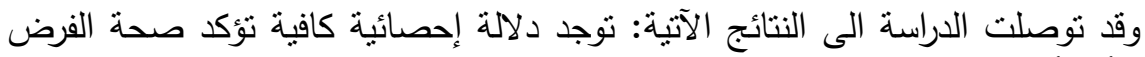

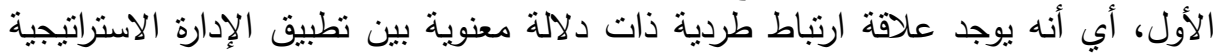

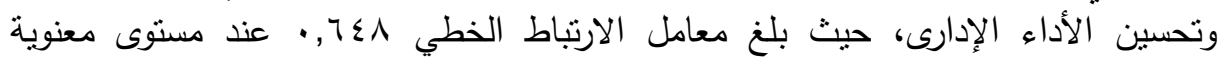

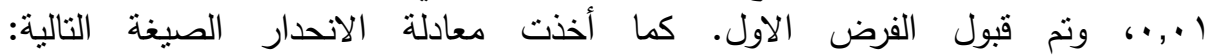
أنه

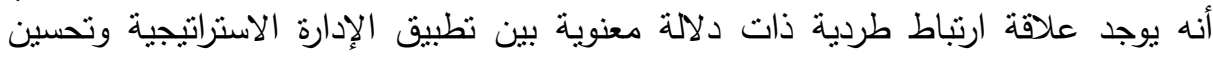

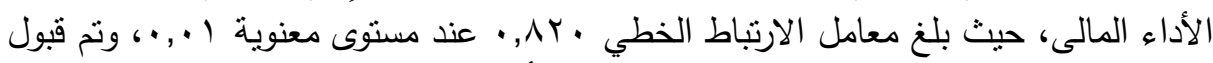
الفرض الثانى. ع +

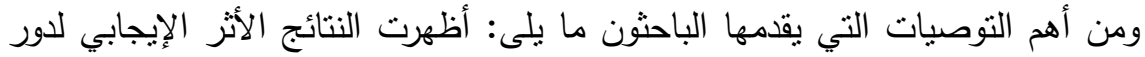

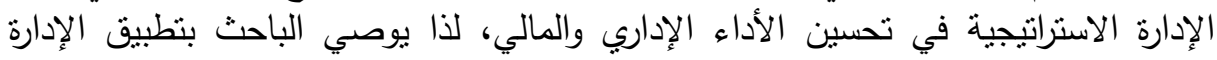

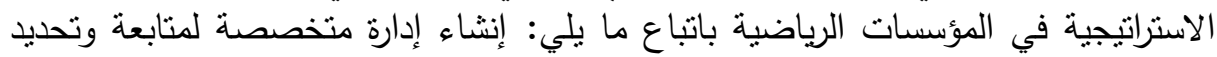

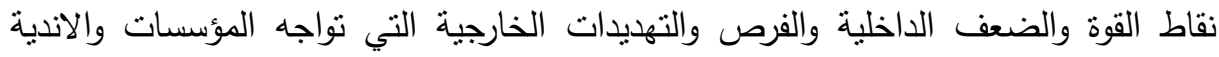

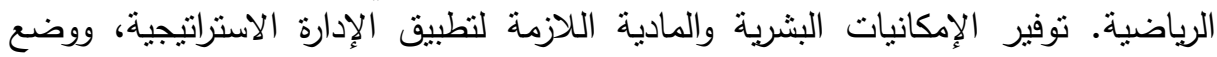

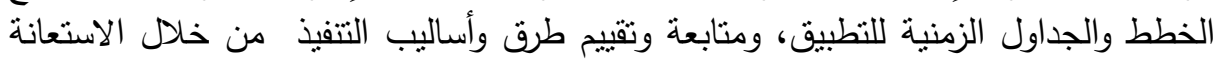
بأفراد يتمتعون بالمهارة اللازمة، والمكانة العلمية والاداء الاحترافئ. 


\section{المهond}

إن الإدارة في مجال المؤسسات الرياضية، هى عملية تخطيط وتنظيم ورقابة وتوجيه وإثراف وإتخاذ قرار ، وهى عملية اجتماعية متجددة ومتكاملة ومستمرة، تستخدم الموارد المتاحة اللوصول إلى هدف محدد في زمن محدد، فإذا جرت الإدارة في إطار نظم الدولة ولوائحها فإِنها

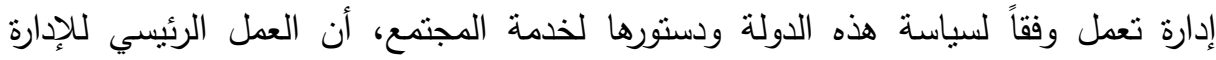
وإستخدامها هو السعي لتحقيق أهداف محددة ترغبها المؤسسة التي تقوم الإدارة بمسئولياتها. وتثير الإدارة الإستراتيجية إلى التوجه الإداري الحديث في تطبيق الدذخل الإستراتيجي

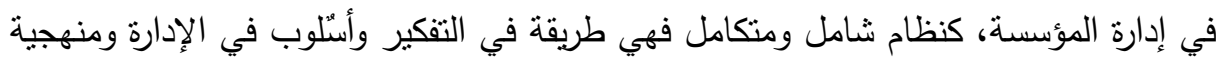
في صنع إنخاذ القرارات الإستراتيجية، فالإدارة الإستراتيجية هي سلسلة من القرانية القرارات والأفعال

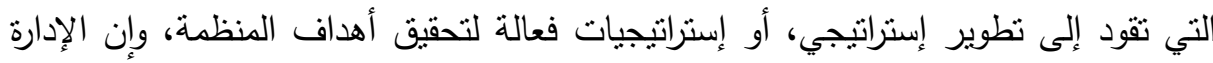

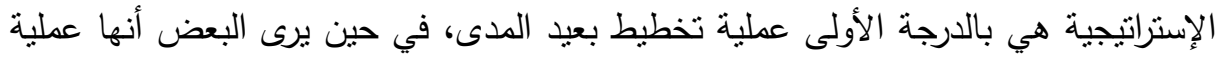

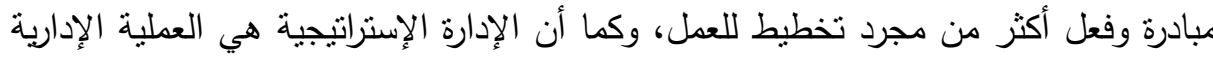

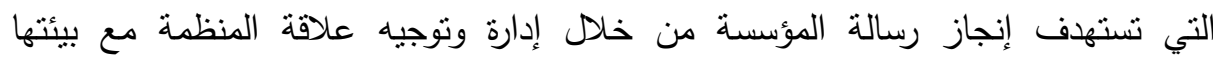

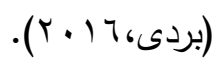

ويتوقف نجاح الإدارة داخل المؤسسات الرياضية بتوفير رؤوس الأموال، وذلك يتطلب إدارة جيدة تستطيع القيام بأدوارها الادارية والمالية، وهذه الأخيرة تتعلق بوظائف الإدارة الإنة وهي الإني

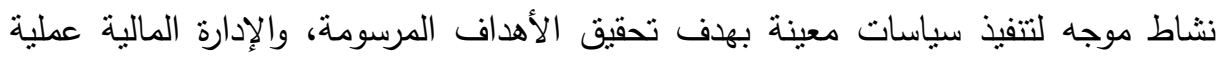
تتسق فيها الجهود وترشد القرارات بهدف الوصول إلى الننائج الإيجابية، أخذين بعين الإعتبار

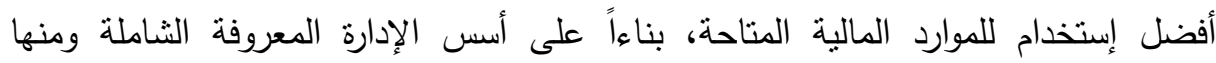

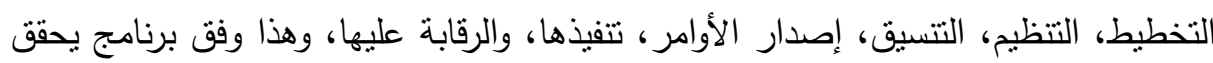

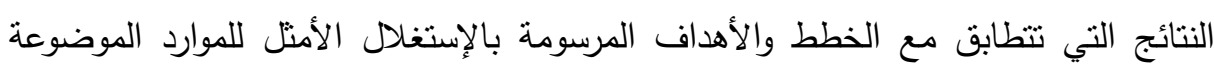

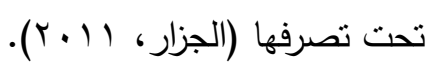

ولهذا تعد الإدارة الإستراتيجية مطلباً يساعد فى تحسين الأداء الادارى والمالى داخل

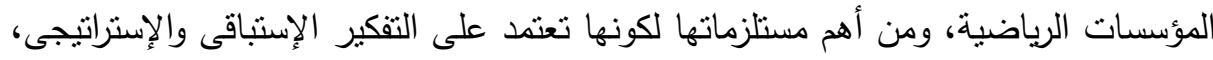

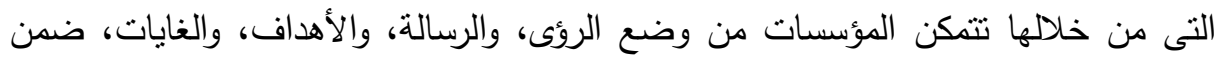


إطار وفكر مستدام يساعد كل أبعاد التتمية المستدامة، وتمكنها من دراسة وتحليل وبيان

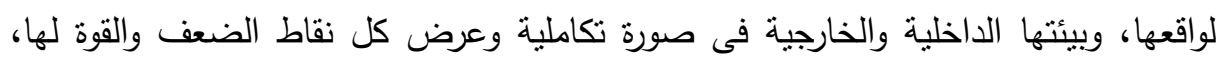

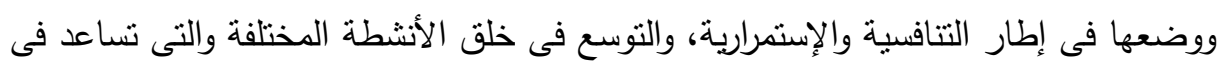
خلق أجيال لديها الدراية الكاملة بعملية التنمية الثاملة للدولة.

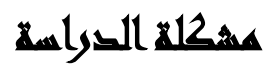

هناك الكثير من المؤسسات الرياضية لا تزال تمارس أساليب إدارية تقليدية، تعكس إلى

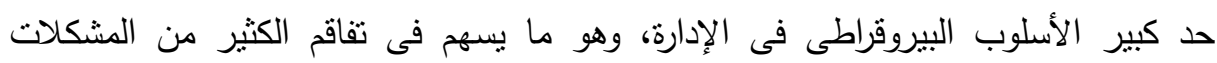
الإدارية، والمالية، والتنظيمية، كالضبابية وعدم الثفافية فى رؤية الرسالة والأهداف للمؤسسات الرياضية المستقبلية وضعف الموارد البشرية والمالية والأنظمة والقوانين، وأدى عدم فهم الإدارة العليا بالمؤسسات الرياضية لمفهوم الإدارة الإستراتيجية، ذلك المفهوم الحديث الذئى تتبعه كل

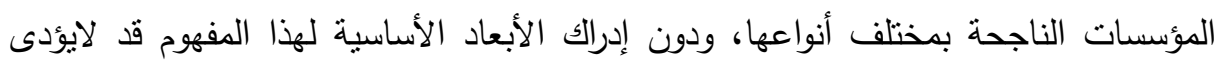
الى تحقيق النتائج المنوقعة.

ومن خلال إطلاع الباحثون على الدراسات السابقة، لوحظ أن دراسة (Oschlies,2013) الإستراتيجية، في صناعة الطاقة المتجددة، ويمكن لهذه العوامل بعد ذللك توجيه المديرين، ومجالس الإدارة، وصانعي السياسات، والمستثمرين في عمليات صنع القرار في المستقبل، أما

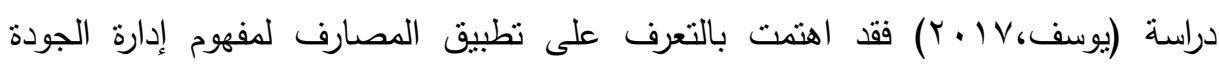

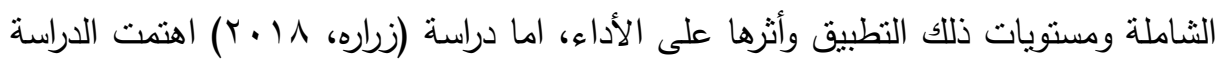

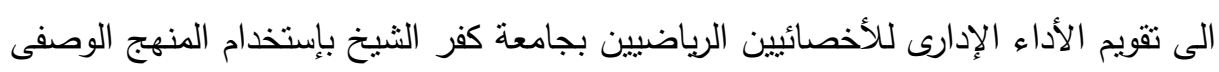

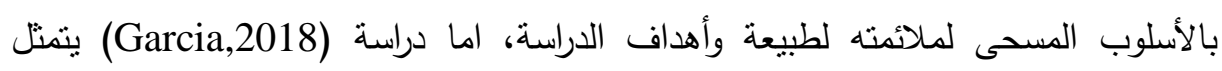

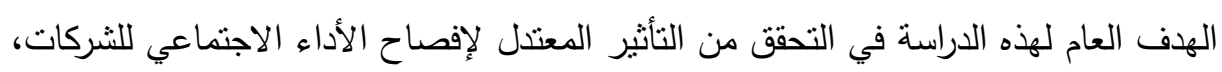

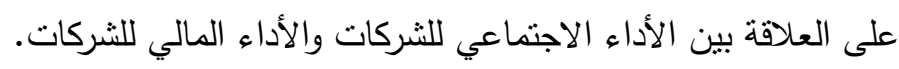

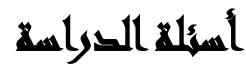

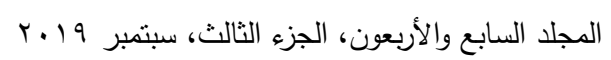




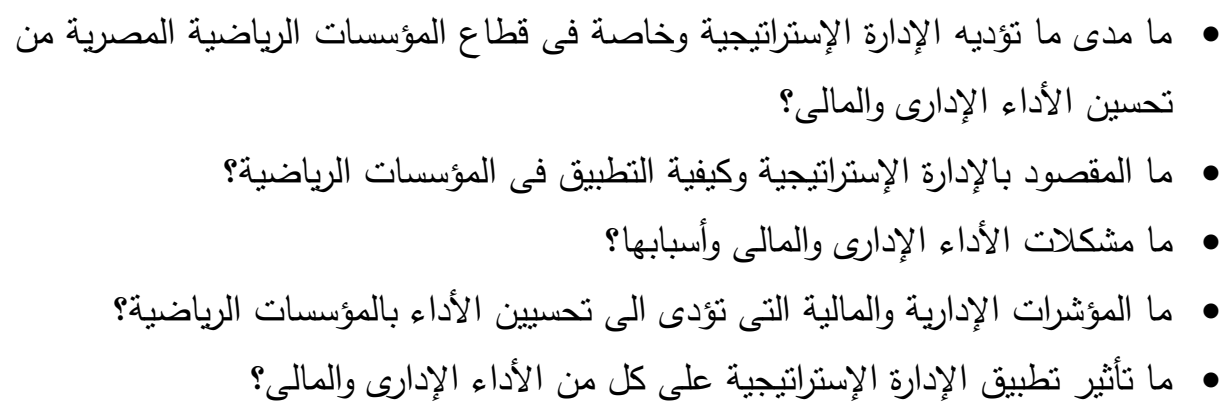

\section{أهمري التصواسم}

من الناحية العلمية: تتبع الأهمية من فتح مجالات أمام الباحثين والدارسين للإطلاع على نماذج الإدارة الإستراتيجية، والمقارنة بين نقاط القوة والضعف ومحاولة تطويرها وتحسينها، توضيح العلاقات بين متغيرات الدراسة لإظهار الصورة للإدارة العليا بالمؤسسات الرياضية وإنخاذ القرارات الصحيحة.

من الناحية التطبيقية: تقديم توصيات لكافة أنواع المؤسسات الرياضية وتفعيل إستخدام الإدارة الإستراتيجية للمساعدة فى تحسين الأداء بشكل عام، والأداء الإدارى والمالى بشكل خاص.

\section{أهساهتغ الصواسما}

• توضيح مفهوم الإدارة الإستراتيجية وكيفية التطبيق فى المؤسسات الرياضية. • بيان مشكلات الأداء الإدارى والمالى وأسبابها.

• تحديد المؤشرات الإدارية والمالية التى تؤدى الى تحسين الأداء فى المؤسسات الإداء الرياضية. • بيان تأثنير تطبيق الإدارة الإستراتيجية على كل من الأداء الإدارى والمالى. 


\section{هغوغ الترالها}

في ضوء أهداف الدراسة قام الباحث بصياغة الفروض الثالية، بهدف إختبارها والتحقق من هرغ

صحتها:

الفرض الأول: يؤدي تطبيق الإدارة الاستراتيجية في المؤسسات الرياضية إلى تحسين الأداء

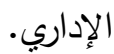

الفرض الثاني: يؤدي تطبيق الإدارة الاستراتيجية في المؤسسات الرياضية إلى تحسين الأداء

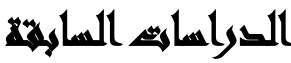

دراسة عبد التواب (Y V • V): وقد هدفت الدراسة إلى التعرف على واقع ممارسة الإدارة الإستراتيجية بقطاع التعليم بمصر، ذلك القطاع الذى بعد من أهم القطاعات التى ثُنبى عليها الدولة ، وقد توصلت هذه الدراسة الي هذه النتائج: بأن هناك ممارسة جيدة إلى حد ما لمراحل

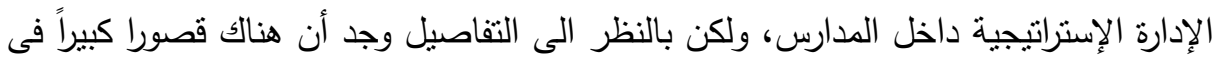
توافر أغلب الخطوات المكونة للمراحل، الى جانب قصور الفهم من جانب كافة العاملين للهدف والأهمية من تطبيق الإدارة الإستراتيجية بمدرستهم، وهذا يفسر النتيجة التى أظهرت عدم تحسن الأداء بتلك المدارس خلال السنوات الخمس الماضية.

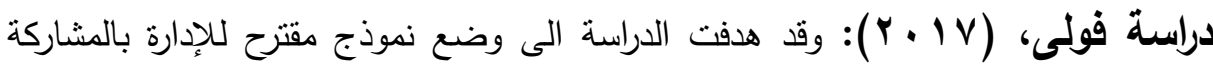

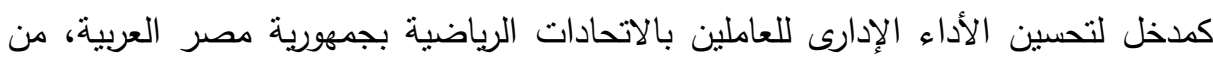

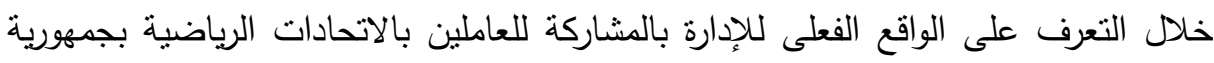

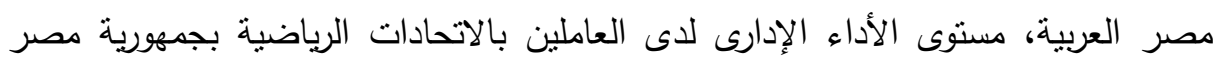

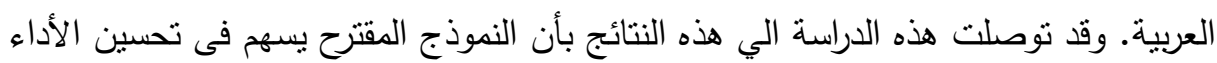
الإدارى للعاملين بالاتحادات الرياضية بجمهورية مصر العربية. 
دراسة حسين، (YV P P): وقد هدفت الدراسة الى التوصل الى إطار لدمج الإعنبارات

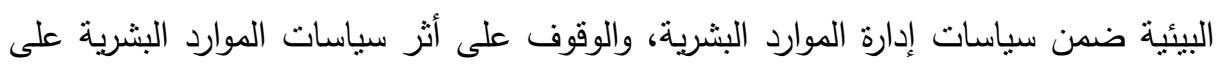

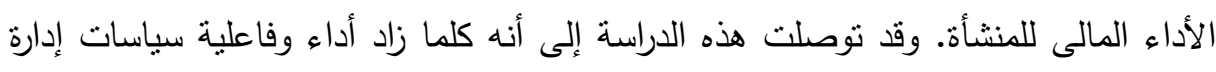
الموارد البشرية، كلما زاد أداء وفاعلية الأداء المالى، وبوجود أهمية قصوى للإعتبارات البيئية

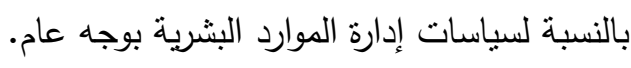

دراسة (Vreuls,2013): وقد هدفت الدراسة الى تصميم حل لهشكلة عملية، وهي كيفية تكييف تقديم الخدمة الخبرة للأندية التي تختلف في أسلوب إدارة المعرفة، وذلك لإيجاد إداد حل لهذه المشكلة وفهم أسباب المشكلة. وقد توصلت هذه الدراسة الي أنه يوجد تأثير كبير لحجم الثركة في أساليب إدارة المعرفة، الأندية الكبيرة من إيردفيسيل لديها القدرة على التعامل

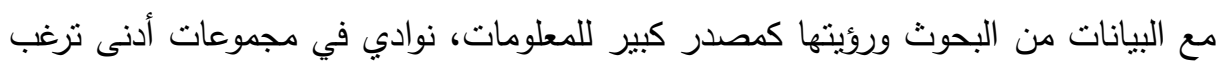
في روية أفضل الممارسات والفرص المتاحة لتحليل البيانات. دراسة (Oschlies,2013): وقد هدفت الدراسة الى تحديد عوامل النجاح والمخاطر للإدارة الإستراتيجية، في صناعة الطاقة المتجدة، ويمكن لهذه العوامل بعد ذلك توجيه

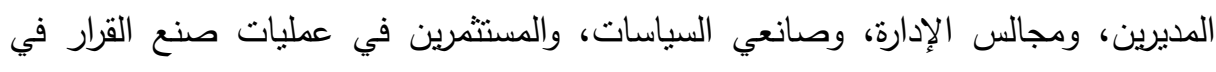

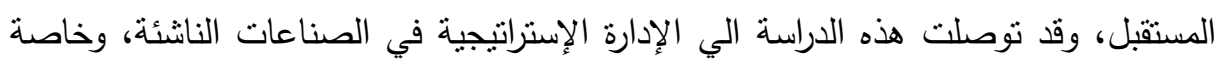

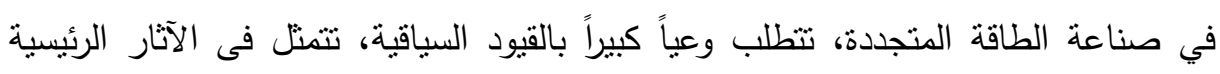
للمديرين والمستثرين وصانعي السياسات فيما يلي: يجب أن تكون القرارات الإستراتيجية منوافقة تماماً مع أصحاب المصلحة لضمان التتفيذ وخلق ميزة تتافسية. دراسة (Sorina-Geanina stanescu1,2018): وقد هدفت الدراسة إلى تحديد الرابط بين الموارد البشرية، المعبر عنها عددياً من قبل عدد الموظفين، ومؤشرات الأداء المالي المسجلة على مستوى الكيان التجاري، تحليل الترابط بين المتغير التابع (عدد الموظفين)

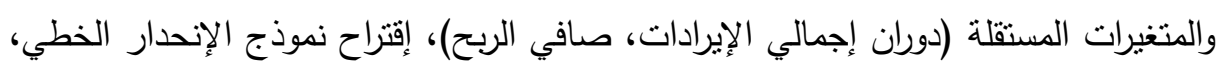

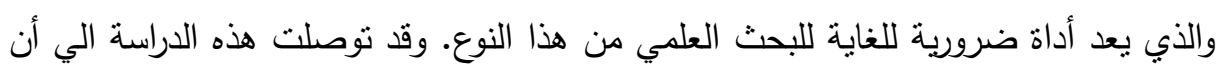
هناك صلة مباشرة، وربما متتاسبة ، بين عدد الموظفين واثثين من المتغيرات المستقلة، دوران وإجمالي الدخل، فيما يتعلق بالعلاقة بين عدد الموظفين وصافي الربح.

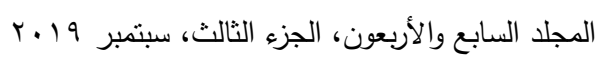




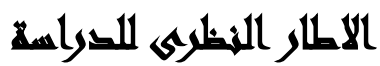

تتاولت الدراسة مجموعة من المفاهيم بالتوضيح أهمها (الإدارة، الإدارة الإستراتيجية، الأداء الإدارى للمؤسسات، الأداء المالى للمؤسسات). مفهوم الإدارة: إن الإدارة في مجال المؤسسات، لا تخرج في مفهومها ووظائفها عن كونها عملية تخطيط وتتظيم ورقابة وتوجيه وإشراف وإتخاذ قرار، وهى عملية اجتماعية متجددة ومتكاملة ومستمرة، نستخدم الموارد المتاحة للوصول إلى هدف محدد في زمن محدد، فإذا جرت الإدارة في إطار نظم الدولة ولوائحها فإنها إدارة تعمل وفقاً لسياسة هذه الدولة ودستورها لخدمة الصالح العام للمجتمع. ومن مجمل الأفكار المتداولة عن الإدارة اتضحت حقيقة أساسية، أن العمل الرئيسي للإدارة ومبرر وجودها ومقياس نجاحها هو السعي لتحقيق أهداف

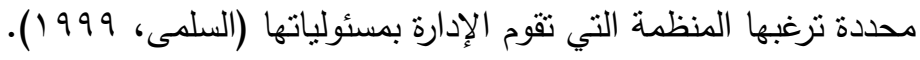
الإدارة الإستراتيجية: عرف كوتلر الإدارة الإستراتيجية علي أنها العملية التي يتم من خلالها

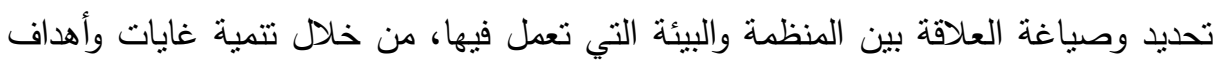
وإستراتيجيات النمو وتحديد محفظة الأعمال لكل العمليات والأنشطة التي تمارسها المنظمة فينة (Kotler, 1980)، أما جوليك عرفها علي أنها خطة موحدة ومتكاملة وشاملة تربط بين المزايا التتافسية للمنظمة والتحديات البيئية (Jauch and Glueck, 1988)، ويعرفها بيرنارد بأنها

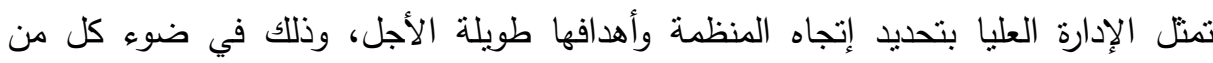
العوامل البيئية الداخلية (إمكانيات المنظمة) والخارجية (الظروف البيئية المحيطة)، ثم تطبيق الإستراتيجية المختارة والرقابة عليها (Burnes, 2004).

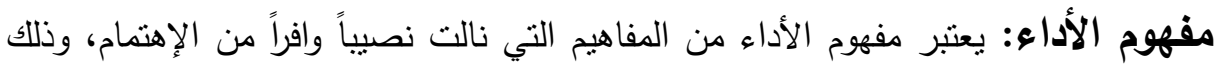
لأهمية المفهوم على مستوى الفرد والمؤسسة، ولتداخل المؤثرات التي تؤثنر على الأداء

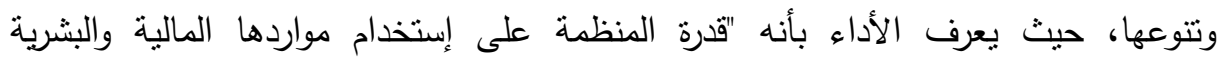
والتكنولوجية والمعرفية بالصورة التي تجعلها قادرة على تحقيق أهدافها بطريقة كفؤ وفعالة وتحقق نوقعات وتطلعات أصحاب المصالح (Michael, 2006).

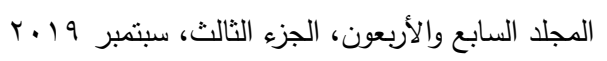


الأداء الإدارى للمؤسسات: عرف الباحثون الأداء الإداري داخل المؤسسات الرياضية

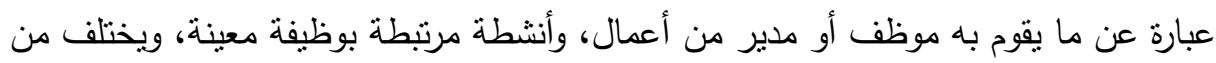

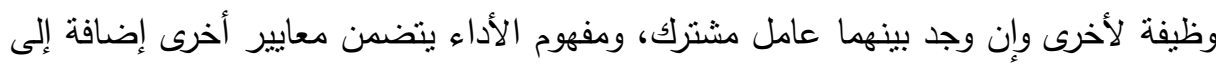

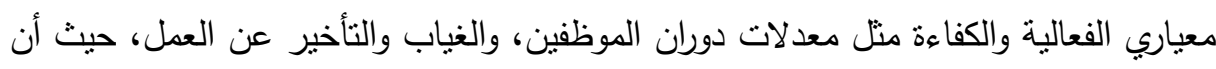
العامل الجيد هو الذي تكون إنتاجيته عالية، وكذلك يسهم أداؤه في تقليل المشاكل المرتبطة

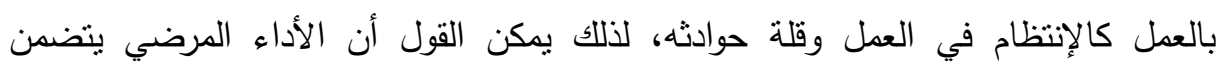
مجموعة من المتغيرات من حيث أداء العمل بفعالية وكفاءة مع حد أدنى من المشاكل والمعوقات والسلبيات الناجمة عن سلوكه في العمل. الأداء المالى للمؤسسات: يعرف الأداء المالي بأنه العوائد التي تحصل عليها الثركة من لمن

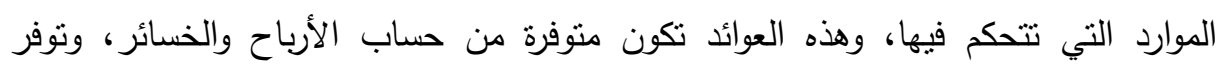

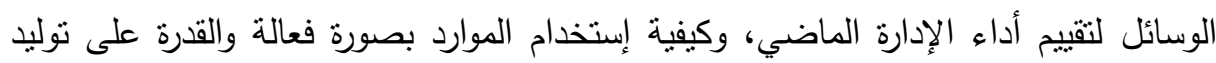

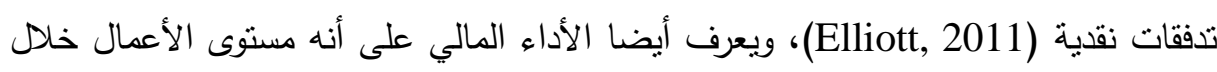
فترة محددة من الزمن، عبر عنه بوجه عام بمصطلحات الأرباح والخسائر خلال نلك الفترة،

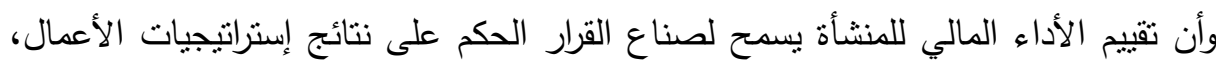
وأنشطتها من الناحية النقدية الموضوعية (financial_performance, 2015).

\section{اجبراءاهي القراسمة}

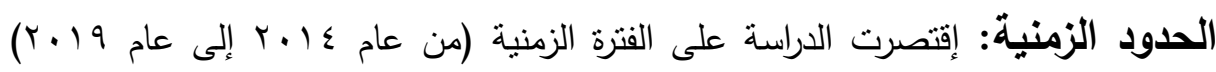

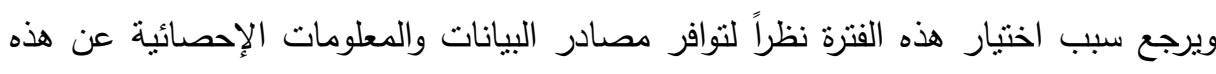
الفترة والتي سوف يعتمد عليها الباحث. الحدود المكانية: بعض المؤسسات والاندية الرياضية بمدينة القاهرة. منهجية الدراسة: أسلوب الدراسة: تعتىد الدراسة علي المنهج الوصفي التحليلي SAnalytical Descriptive Approach كثير من البحوث والدراسات الخاصة تلك التي تتتاول ظواهر اجتماعية تتعلق بالممارسات 
اليومية حيث تم الاطلاع على عدد من البحوث والدراسات المنشورة في الدوريات والمجلات العلمية المتخصصة، وكذللك المنشورة على شبكة الإنترنت بالإضافة إلى الاطلاع على آلى آليات وقواعد الحوكمة الصادرة عن المنظمات والهيئات العالمية المحلية. الدراسة النظرية: حيث إعتمد الباحث على مجموعة من التقارير والنشرات والاحصاءات

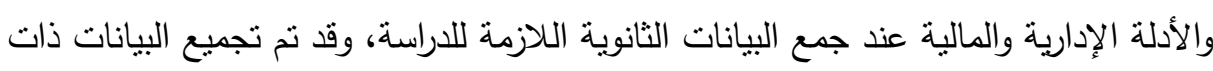
الصلة بالأداء الإدارى والمالى للمؤسسات الرياضية الماليه المصرية.

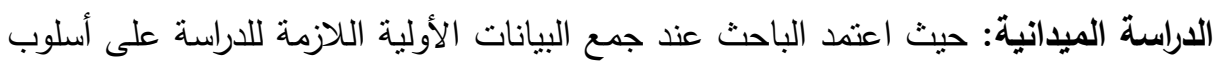
الملاحظة والاستقصاء حيث تم سؤال مفردات مجتمع البحث عن ذللك لقياس دور الإدارة

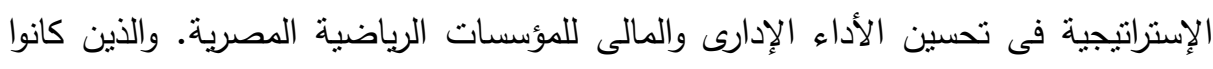

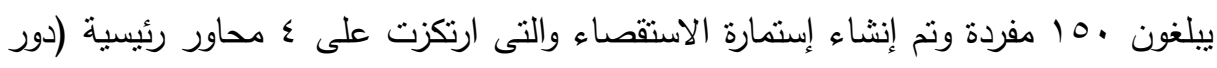

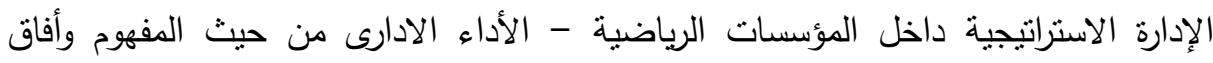
التطوير - الأداء المالى من حيث الاهمية والاهداف - دور الإدارة الاستراتيجية في تحسين

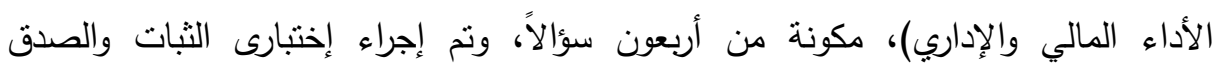
بهدف معرفة مدى صدق وصحة وصلاحية قائمة (Reliability and Validity tests) الاستقصاء لإجراء التحليلات الإحصائية اللاحقة. والجدول (1) يوضح نتائج تطبيق كلاً من اختباري الثبات والصدق على مستوى لإهى 
جدول (1) - نتائج تطبيق معاملي الثبات والصدق

\begin{tabular}{|c|c|c|c|}
\hline |لصدق (*) & $\begin{array}{l}\text { معامل الثبات } \\
\text { Alfa }\end{array}$ & 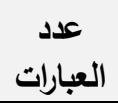 & 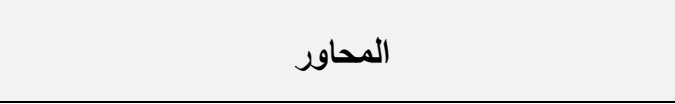 \\
\hline$\cdot, \vee \wedge \vee$ & $\cdot, 7 / 9$ & 1 . & المحور الأول: دور الإدارة الاستراتيجية داخل المؤسسات \\
\hline$\cdot, \wedge 94$ & $\cdot, \vee \vee 90$ & 1. & المحور الثاني: الأداء الإداري (المفهوم - آفاق التطوير) \\
\hline$\cdot, \wedge 0 \leqslant$ & $\cdot, \mathrm{VT} \cdot$ & 1. & المحور الثالث: الأداء المالى (الأهية - الأهداف). \\
\hline$\cdot, 9 \cdot 7$ & $\cdot, \wedge r$ & 1. & المحور الرابع: دور الإدارة الاستراتيجية فى تحسين الأداء \\
\hline$\cdot, 91 \mathrm{r}$ & $\cdot, \wedge r$ & $\varepsilon$. & قائمة الاستقصاء \\
\hline
\end{tabular}

Structure معامل الصدق هو الجذر التربيعي لمعامل الثبات، ويقصد به الصدق البنائي

Validity

يتضح من الجدول أن معاملات الثبات والمتمنلة في معاملات Conbatch's Alpha

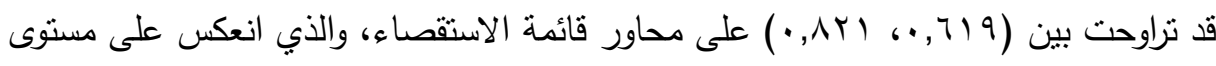

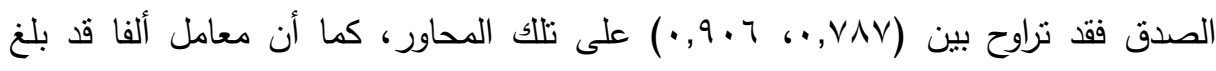

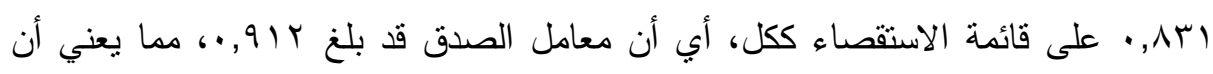

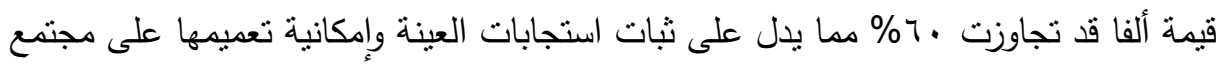

$$
\text { الدراسة. }
$$

وكمصلة نهائية يمكن القول أن قائمة الاستقصاء تقيس ما وضعت لقياسه وبالتالي

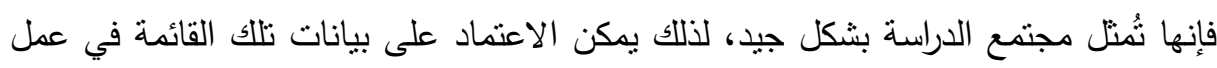
التحليلات والاختبارات الإحصائية اللاحقة. ومن هنا نم الانتقال إلى المرحلة الثالثة من عملية لثئي

$$
\text { اعداد وتجهيز البيانات وهي تكوين متغيرات الدراسة. }
$$

مجتمع وعينة الاراسة: مجتمع الدراسة: يتمثل مجتمع الدراسة في مجالس إدارات

$$
\text { والمديرين بالمؤسسات الرياضية المصرية. }
$$

عينة الاراسة: وقد نم سحب عينة متعددة المراحل Multi Stages Sample، حيث تم

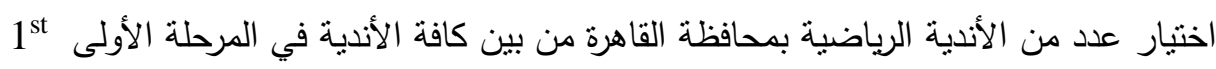

stage، وقد تم الاختبار بناءً على عدد من المعايير نذكر منها: 


$$
\begin{aligned}
& \text { سهولة الحصول على المعلومات. } \\
& \text { القرب من محل السكن. } \\
& \text { • المستوى العلمي لأعضاء مجلس الإدارة والمديرين. }
\end{aligned}
$$

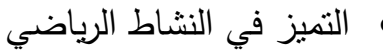

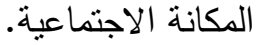

$$
\begin{aligned}
& \text { التتوع بين الأندية الحكومية والخاصة. }
\end{aligned}
$$

وقد قام الباحث بسحب عينة حجمها ـ 10 فرداً من المسئولين بالأندية المختارة في المرحلة الثانية nd Stage Sample، وقد راعى الباحث بقدر الإمكان أن يكون توزيع العينة متتاسباً مع عدد المسئولين بكل نادي. الأساليب الاحصائية: عرض الباحث النتائج ومناقتشها في ضوء فروض الدراسة، وذلك في (دور الإدارة الإستراتيجية فى تحسين الأداء الإدارى والمالى).

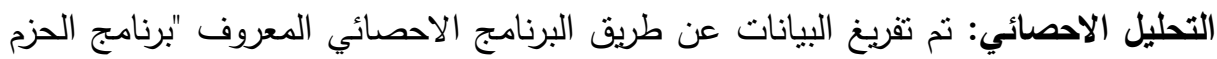
الاحصائية للعلوم الاجتماعية Statistical package for Social Sciences ونم التحليل Microsoft Excel الاحصائي باستخدام الحاسب الآلي باستخدام كلاً من برنامج 2016

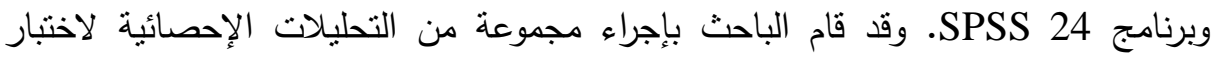
فروض الدراسة ، ومن هنا سوف يتم التحقق من مدى صحة أو عدم صحة فروض الدراسة.

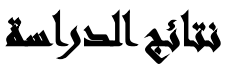

أولاً: نتائج الاراسة التطبيقية: يستعرض الباحث فيما يلي أهم النتائج التي نوصل اليها من خلال الدراسة التطبيقية لدراسة قياس دور الإدارة الإستراتيجية فى تحسين الأداء الإدارى والمالى على بعض المؤسسات الرياضية المصرية، ويمكن تقسيم هذه النتائج الى البنود الآتية: 
بعد دراستتا لمختلف الجوانب المتعلقة بكل من الادارة الاستراتيجية والأداء الإدارى

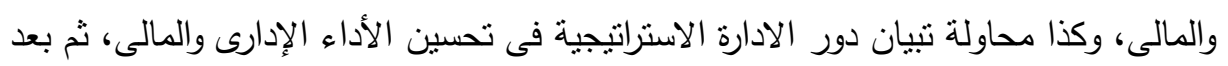
قيامنا بالدراسة الميدانية تمكنا إلى التوصل إلى الى النتائج الثالية:

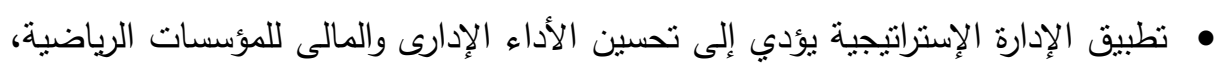
وقد ينسم الأداء بالفعالية والكفاءة.

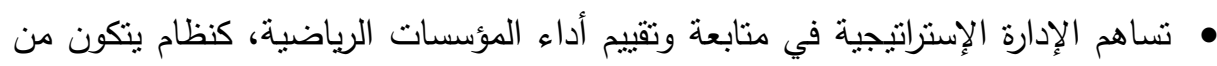
بنية متفاعلة من الأنظمة الوظيفية الفرعية الى جانب تحليل المناخ التنظيمي والثقافة الإنة

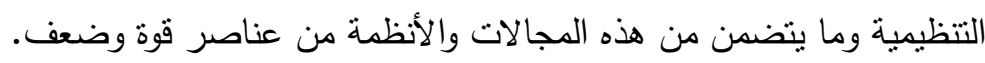
• تقوم الادارة الإستراتيجية بدور كبير في تخطيط مستقبل المؤسسات الرياضية من خلاد

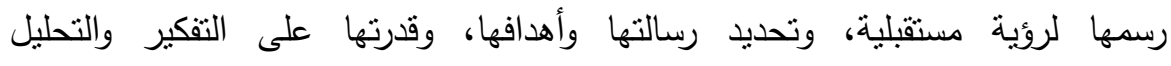
الإستراتيجي وصنع القرارات الإستراتيجية، وتولي صياغة خطة إستراتيجية ومن ثم تتفيذها وتقبيمها. •يؤثر إنباع أسلوب الادارة الاستراتيجية فى المؤسسات الرياضية علي تطوير الأنظمة الإدارية والمالية وذلك من خلال نتبع القبادات بالاساليب الادارية الحديثة.

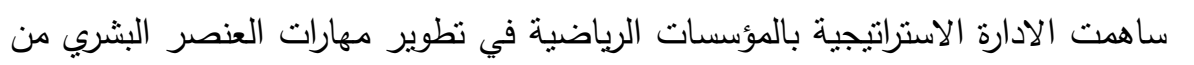

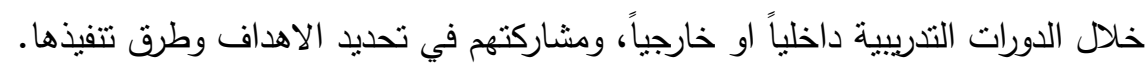
تبين من الدراسة أن تطبيق الإدارة الاستراتيجية له أثر إيجابى على تحسين الأداء الإدارى والمالى، وذللك من خلال ما تحقق من تطور واضح في هذه المؤسسات.

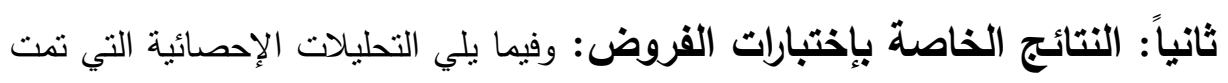
لإختبار مدى صحة أو عدم صحة فروض الدراسة الرئيسية. التحليلات الإحصائية لإختبار الفرض الرئيسي الاول: "يؤدي نطبيق الإدارة الإستراتيجية في المؤسسات الرياضية إلى تحسين الأداء الإداري".

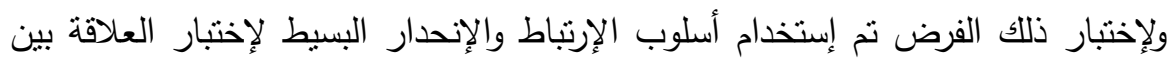
تطبيق الإدارة الإستراتيجية وتحسين الأداء الإداري، وجاءت الإت النتائج التالية: 
جدول (Y): نتائج الإرتباط والإنحدار البسيط لاختبار العلاقة بين تطبيق الإدارة الاستراتيجية وتحسين الأداء الإداري

\begin{tabular}{|c|c|c|c|c|c|c|}
\hline \multicolumn{7}{|c|}{ 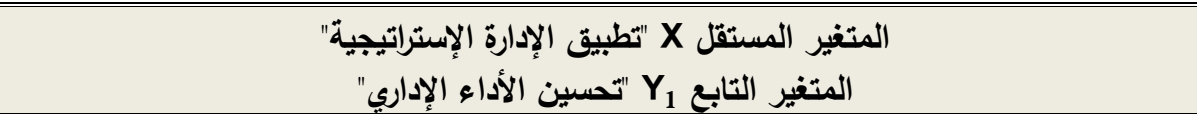 } \\
\hline \multicolumn{3}{|c|}{ اختبار معنوية المعلمات المقدرة } & \multicolumn{2}{|c|}{ اختبار معنوية النموذج } & \multirow{2}{*}{$\begin{array}{c}\text { التقديرة } \\
\text { القية } \\
\text { R }^{2}\end{array}$} & \multirow{2}{*}{$\begin{array}{c}\text { الارتباط } \\
\text { R } \\
\text { R }\end{array}$} \\
\hline $\begin{array}{l}\text { Sig. } \\
\text { المعنوية }\end{array}$ & $\begin{array}{c}\text { T } \\
\text { المحسوبة }\end{array}$ & قيمة المعامل & $\begin{array}{l}\text { Sig. } \\
\text { المعنوية }\end{array}$ & 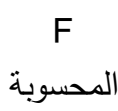 & & \\
\hline$\cdot, \cdots$ & $1 \wedge, \Lambda$ & r,qur & \multirow{2}{*}{$\cdot, \cdots$} & \multirow{2}{*}{$1 \cdot V, r$} & \multirow{2}{*}{$\cdot, \varepsilon r$} & \multirow{2}{*}{$(* *) \cdot, 7 \leq \wedge$} \\
\hline$\cdot, \ldots$ & $1 \cdot, \varepsilon$ & $\cdot, \Gamma \leqslant 7$ & & & & \\
\hline
\end{tabular}

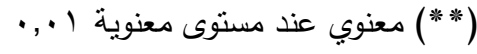

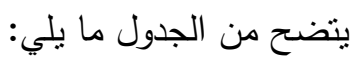

أظهرت نتائج الارتباط وجود علاقة طردية ذات دلالة معنوية بين تطبيق الإدارة

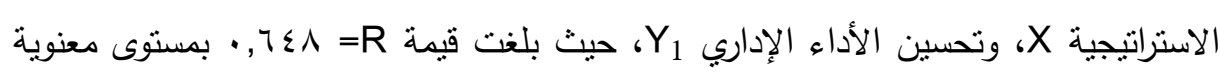

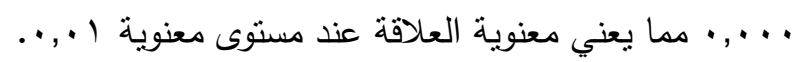

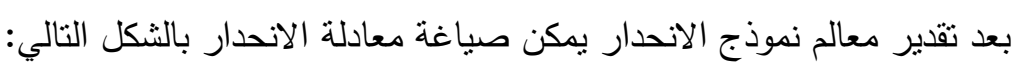
$Y_{1}=2.933+0.346 * X+\varepsilon$

حيث: YY "تحسين الأداء الإداري" (المتغير التابع)؛ X X "تطبيق الإدارة الاستراتيجية" (المتغير المستقل)؛ ع الخطأ العثوائي.

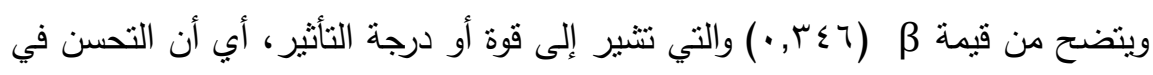

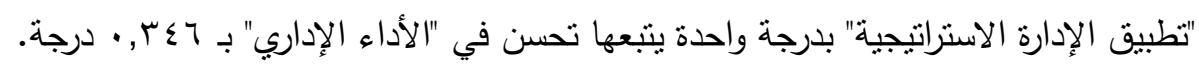

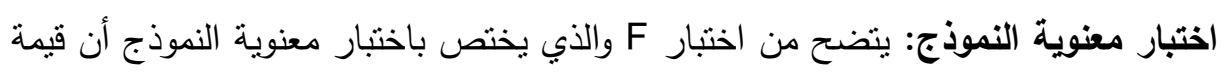

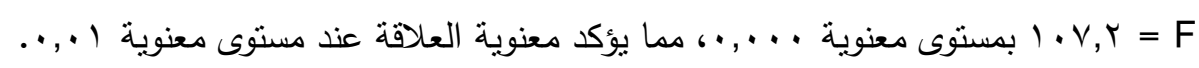

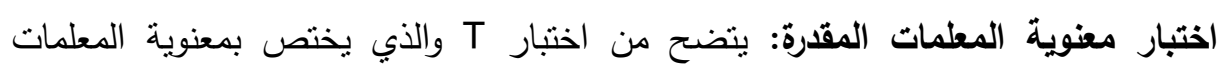

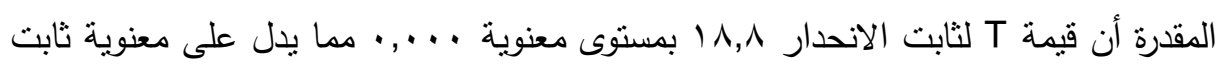

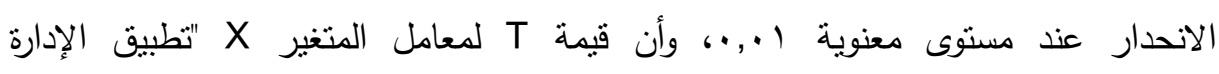


الاستراتيجية" قد بلغ ع, . ا بمستوى معنوية . .., . مما يؤكد معنوية معامل المتغير المستقل عند مستوى معنوية ال,.,.

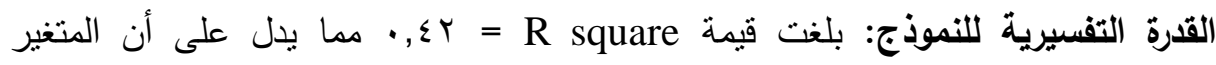

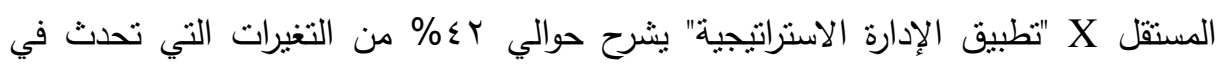
المتغير التابع Y1 "تحسين الأداء الإداري" في المؤسسات الرياضية، ويوضح شكل الإدئه لأنتاشر التالي العلاقة بين تطبيق الإدارة الاستراتيجية وتحسين الأداء الإداري في المؤسيسات الرياضية:

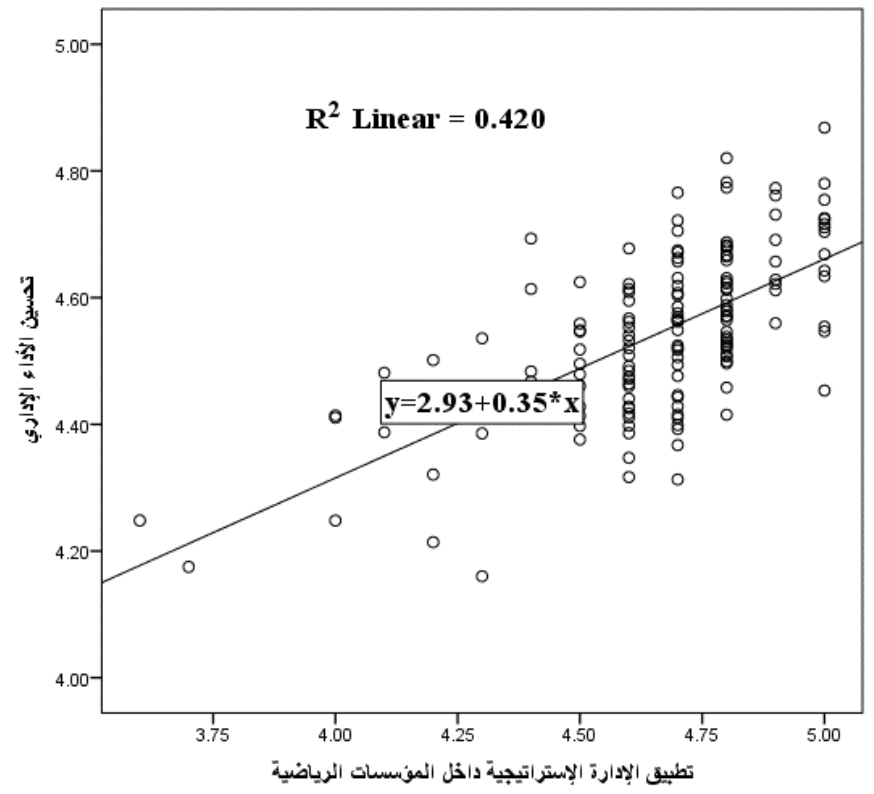

شكل (1): العلاقة بين تطبيق الإدارة الاستراتيجية وتحسين الأداء الإداري في المؤسسات

$$
\text { الرياضية }
$$

نخلص مما سبق إلى قبول الفرض الأول للباحث حيث أنه: توجد دلالة إحصائية كافية

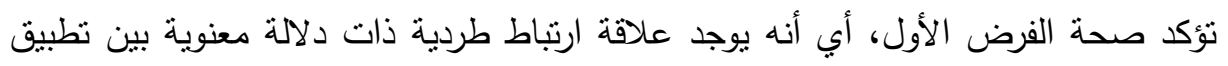

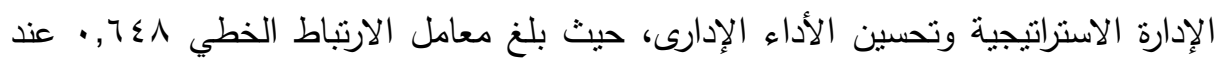

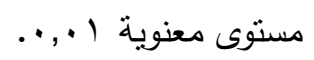


التحليلات الاحصائية لاختبار الفرض الرئيسي الثاني: "يؤدي تطبيق الإدارة الاستراتيجية في المؤسسات الرياضية إلى تحسين الأداء المالي".

ولاختبار ذلك الفرض نم استخدام أسلوب الارتباط والانحدار البسيط لاختبار العلاقة بين

تطبيق الإدارة الاستراتيجية وتحسين الأداء المالي، وجاءت النتائج التالية: جدول (؟): نتائج الارنباط والانحدار البسيط لاختبار العلاقة بين تطبيق الإدارة الاستراتيجية

\begin{tabular}{|c|c|c|c|c|c|c|}
\hline \multicolumn{7}{|c|}{ وتحسين الأداء المالي } \\
\hline \multicolumn{3}{|c|}{ اختبار معنوية المعلمات المقدرة } & \multicolumn{2}{|c|}{ اختبار معنوية النموذج } & \multirow{2}{*}{ التفبيرية } & \multirow{2}{*}{$\begin{array}{c}\text { الارتباط } \\
\text { R } \\
\text { R }\end{array}$} \\
\hline $\begin{array}{l}\text { Sig. } \\
\text { المعنوية }\end{array}$ & $\begin{array}{c}\text { T } \\
\text { المسوبة }\end{array}$ & قيمة المعامل & $\begin{array}{l}\text { Sig. } \\
\text { المعنوية }\end{array}$ & $\begin{array}{c}\text { F } \\
\text { المحسوبة }\end{array}$ & & \\
\hline$\cdot, \cdots$ & $r V, \Lambda$ & r,^9r $\alpha$ & \multirow{2}{*}{$\cdot, \cdots$} & \multirow{2}{*}{$r \cdot r, 0$} & \multirow{2}{*}{$\cdot, T V Y$} & \multirow{2}{*}{$(* *) \cdot, \wedge r$} \\
\hline$\cdot, \cdots$ & $1 V, \varepsilon$ & $\cdot, \Gamma \wedge \wedge \quad \beta$ & & & & \\
\hline
\end{tabular}

(***) معنوي عند مستوى معنوية ل .,.

يتضح من الجدول ما يلي: أظهرت نتائج الارتباط وجود علاقة طردية ذات دلالة معنوية

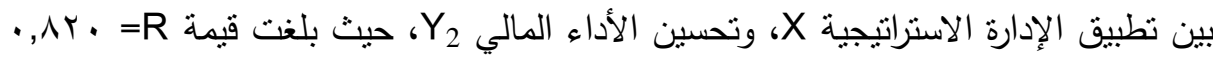

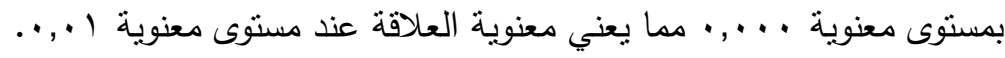

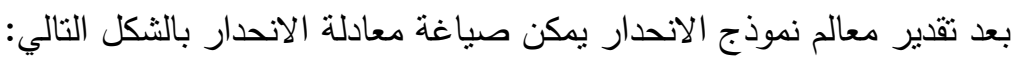

$$
Y_{2}=2.892+0.388^{*} X+\varepsilon
$$

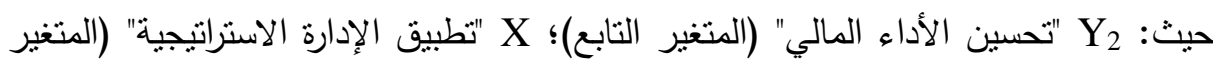
المستقل)؛ ع الخطأ العشوائي.

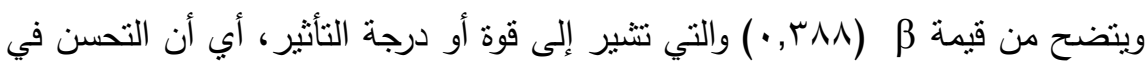

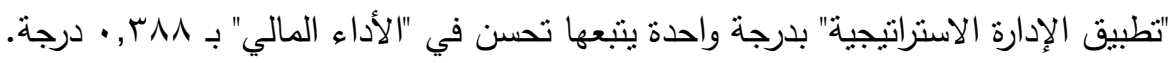

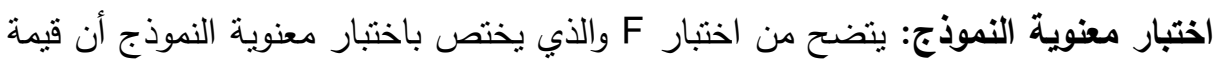

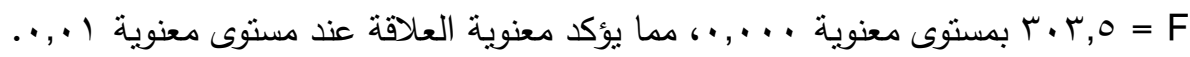


اختبار معنوية المعلمات المقدرة: يتضح من اختبار T والذي يختص بمعنوية المعلمات

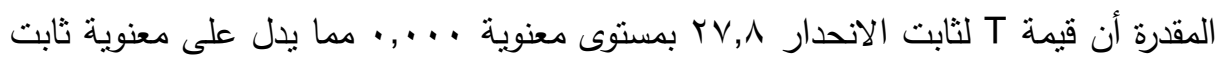

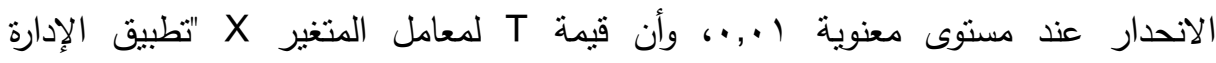

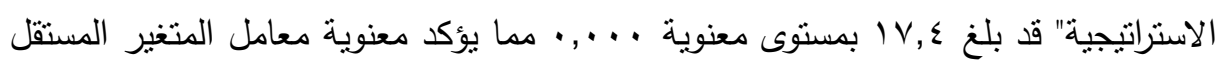
عند مستوى معنوية الم.,... القدرة التفسيرية للنموذج: بلغت قيمة T

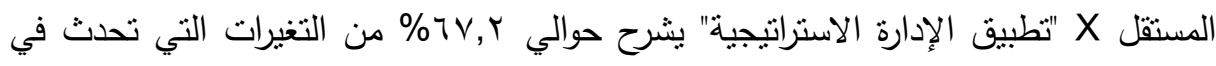

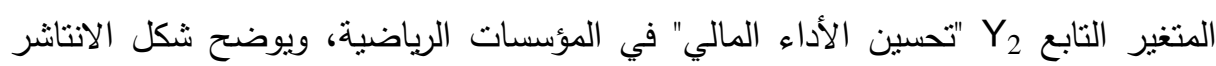
التالي العلاقة بين نطبيق الإدارة الاستراتيجية وتحسين الأداء المالي في المؤسسات الرياضية:

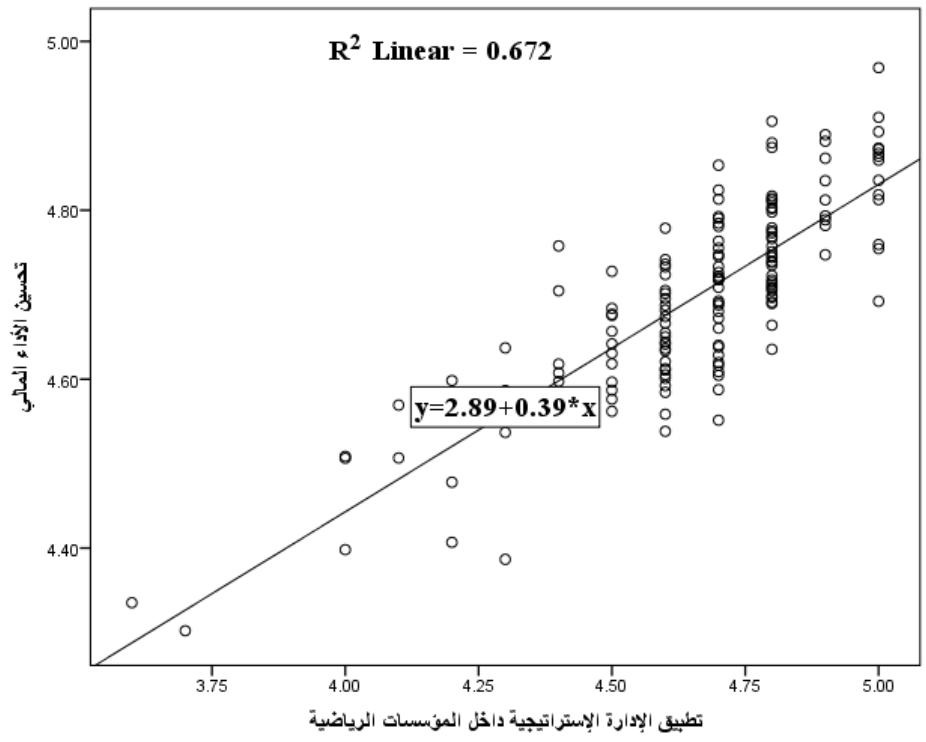

شكل (r): العلاقة بين تطبيق الإدارة الاستراتيجية وتحسين الأداء المالي في المؤسسات الرياضية

نخلص مما سبق إلى قبول الفرض الثاني للباحث حيث أنه: نوجد دلالة إحصائية كافية

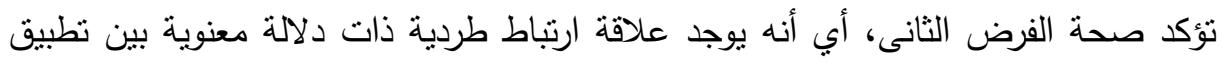

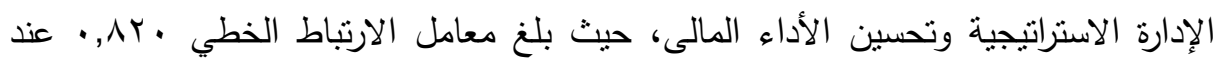




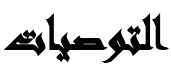

أظهرت النتائج الأثر الإيجابي لدور الإدارة الاستراتيجية في تحسين الأداء الإداري

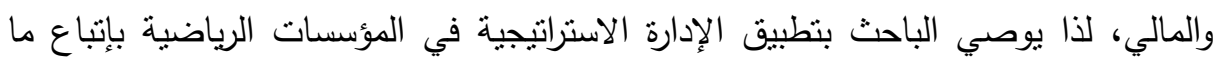

• استخدام معايير ومؤشرات قياسية وموضوعية لتقييم نطبيق الإدارة الاستراتيجية في المؤسسات الرباضية، ومعرفة نقاط القوة والضعف والفرص والتهديدات الداخلية والخارجية التي تواجه تلك المؤسسات. توفير الإمكانيات البشرية والمادية اللازمة لتطبيق الإدارة الاستراتيجية، ووضع الخطط والجداول الزمنية للنطبيق، ومتابعة وتقييم طرق وأساليب التتفيذ.

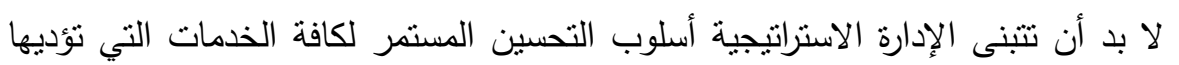

$$
\text { المؤسسات الرياضية. }
$$

ضرورة مواكبة التغيرات العالمية واكتساب المزيد من التعلم والخبرة والقدرة على التفكير الاستراتيجي والاستجابة السريعة للاحتياجات المستقبلية. • ضرورة توافق الهيكل التظيمي للمؤسسات الرياضية مع الإدارة الاستراتيجية.

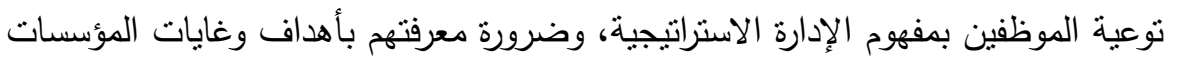
التي ينتمون إليه، وضرورة إثراكهم في اتخاذ القرارارت الاستراتيجية.

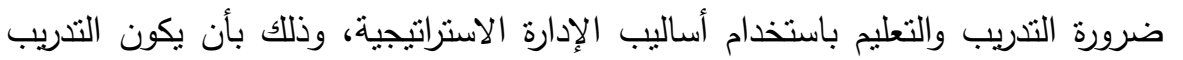
وفق احتباجات كل وظيفة، ووفق خطة استراتيجية واضحة المعالم.

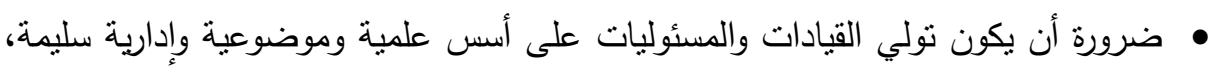
ووفق اختبارات تتناسب مع طبيعة العمل الذي سيوكل إليهم. 
• ضرورة الاطلاع على تجارب المؤسسات الرياضية الناجحة، واتخاذهم كمراجع Benchmarking لمحاكاتهم، ونقل تجاربهم، والاستفادة من خبراتهم. • ضرورة إثراك العاملين والمستقيدين من الخدمات الرياضية عند إعداد الموازنات المالية،

$$
\text { كي يتم الصرف على الاحتياجات الفعلية. }
$$

• ضرورة الاهنمام بالبحث العلمي وتتجيعه، والاستفادة من نتائج تلك البحوث، بمات بؤدي

$$
\text { إلى رفع مسنوى المؤسسات الرياضية. }
$$

بحوث مقترحة: استكمالاً للمسيرة العلمية اقترح الباحث اجراء عدد من البحوث الهدف منها

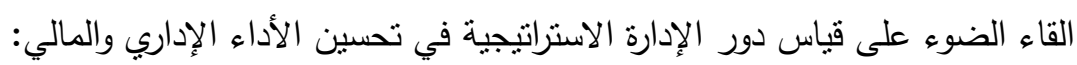
• يقترح الباحث إعداد دراسة عن عدم تطبيق الإدارة الإستراتيجية لمؤسسات الدولة الإداءلة الحكومية. • يقترح الباحث إعداد دراسات في تجارب الدول المتقدمة وكيفية تطبيق الإدارة الإستراتيجية ومدى الإستفادة من تطويرها للأداء وتحسينه.

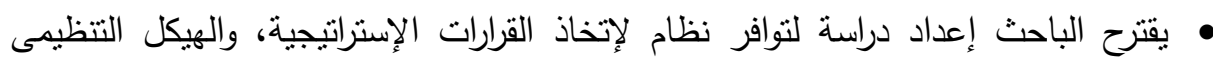
والذى ينوافق مع نطبيق الإدارة الإستراتيجية فى جميع المجالات.

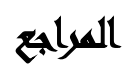

على السلمى (999 (199): الإدارة بالأهداف طريق المدير المتفوق، القاهرة، دار غريب، ص الV.

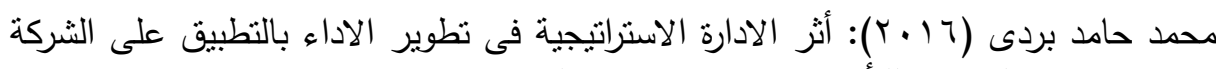

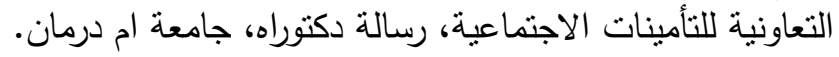

تامر مصطفى الجزار (11 (ب): اللوجستيات كنظام متكامل فى المؤسسات الرياضية، رسالة

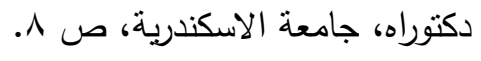

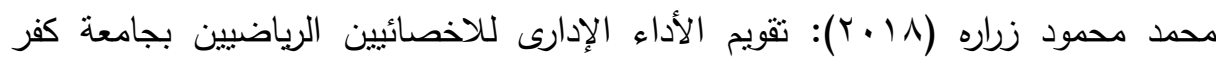
الثيخ، رسالة ماجستير، جامعة كفر الثيخ.

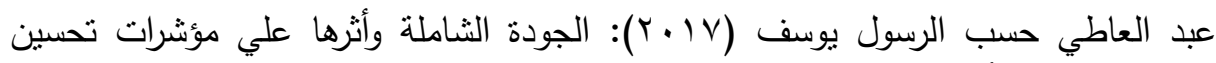

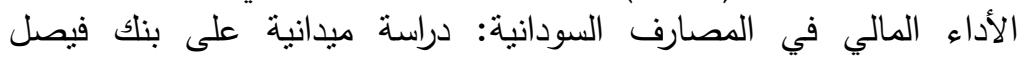
الإسلامي السوداني. رسالة ماجستير ، جامعة أم درمان الإسلامية. 


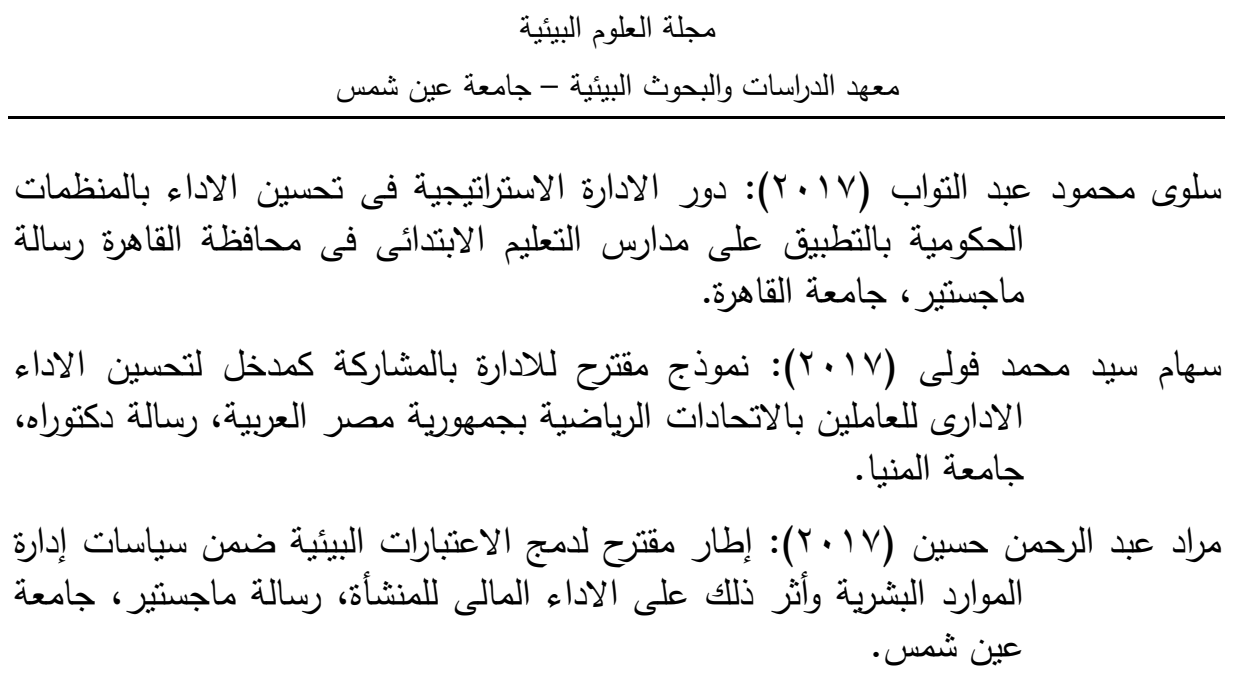

Burnes, Bernard (2004): Managing change: A strategic approach to organizational dynamics, London, Pearson Education, p.91

Elliott B. and Elliott J. (2011): Financial Accounting and Reporting, USA, FT prentice Hall.

Financial_Performance. (2015): http://www.investorwords.com/16429/ financial_performance.html on 2015\08130. [Accessed]

Garcia, Editinete André da Rocha (2018): The influence of social disclosure on the relationship between Corporate Financial Performance and Corporate Social Performance. USP, São Paulo rv. 29, p.229-245.

Jauch, Lawrence R. and Glueck, William F. (1988): Business policy and strategic management, Aukland, McGraw-Hill, p.8.

Kotler (1980): Marketing Management- Analysis- Planning and control, London, Prentice, Hall inc, p-p 64-65.

Michael, Armstrong (2006): Performance Management Key Strategies and Practical Guidelines, London and Philadelphia, Kogan Page Limited, p. 56.

Oschlies, Melanie Katharina (2013): Strategic Management in Emerging Industries: Evidence from the Renewable Energy Industry. doctoral degree, the University of St. Gallen.

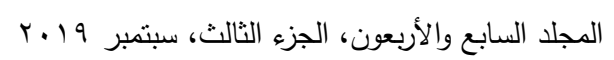


Sorina-Geanina stanescu $1 *$, Alexandra Danila2, Maria-Gabriela Horga2 (2018): Econometric model necessary for analysis of existing correlations between human resources and the financial performance of the enterprises. Journal of Science \& Arts, Vol. 18, p159-166.

Vreuls, Maarten (2013): Improving management and policymaking of Dutch professional football clubs Master Degree, Tilburg University.

\title{
THE ROLE OF STRATEGIC MANAGEMENT IN \\ IMPROVING ADMINISTRATIVE AND FINANCIAL PERFORMANCE \\ APPLIED STUDY ON SOME EGYPTIAN SPORTS INSTITUTIONS
}

Amr M. Hassan ${ }^{(1)}$; Gamal Khattab ${ }^{(2)}$ and Mahmoud Hamed ${ }^{(2)}$ 1) Xerox 2) Faculty of Commerce, Ain Shams University

\begin{abstract}
The objective of the study was to study the strategic management methods and determine the extent of their impact on improving the administrative and financial performance of the sports institutions. In order to achieve the objectives of the study, the inductive method was used in the theoretical study and the field was prepared on the questionnaire for 150 sample items, Health of study hypotheses.

The study reached the following results: Acceptance of the first hypothesis: The results showed a significant correlation between the application of strategic management and improvement of administrative performance; the correlation coefficient was 0.648 at a significant level of 0.01 . $\mathrm{Y} 1=2.933+0.346 * \mathrm{X}+\varepsilon$ The model's significance was $42 \%$.

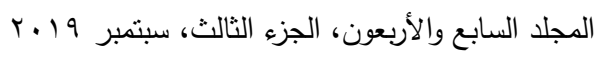


Acceptance of the second hypothesis: The results showed a significant correlation between the implementation of strategic management and the improvement of financial performance; the linear correlation coefficient was 0.82 at a significant level of 0.01 .

$\mathrm{Y} 2=2.892+0.388 * \mathrm{X}+\varepsilon$

The model was validated and the explanatory capacity of the model was $67.2 \%$.

The most important recommendations of the researcher include the following: The results showed the positive impact of the role of strategic management in improving administrative and financial performance. Therefore, the researcher recommends applying strategic management in sports institutions by following the following: Establish a specialized department to follow up and identify internal strengths and weaknesses, opportunities and external threats facing institutions and sports clubs. Provide the human and material resources necessary for the implementation of strategic management, and develop plans and timetables for implementation, and follow-up and evaluation methods and methods of implementation through the use of individuals with the necessary skill, scientific status and professional performance. 